\title{
An Optimized System for the Classification of Meteorological Drought Intensity with Applications in Drought Frequency Analysis
}

\author{
Hugo Carrão, Andrew Singleton, Gustavo Naumann, Paulo Barbosa, and Jürgen V. Vogt \\ Climate Risk Management Unit, Institute for Environment and Sustainability, Joint Research Centre, \\ European Commission, Ispra, Italy
}

(Manuscript received 15 May 2013, in final form 16 April 2014)

\begin{abstract}
The adequacy of meteorological drought intensity threshold levels based on deviations of monthly precipitation totals from normal climatological conditions is reconsidered. The motivation for this study is the observation that reference classification systems are fixed for all climatological regions, and threshold levels have been proposed without regard for the statistical distribution of accumulated precipitation in space and time. This misrepresentation of precipitation variability may lead to erroneous estimates of meteorological drought onset in specific areas where natural breaks in the cumulative distribution of monthly precipitation do not fit the generalized classification systems. In this study, a new optimized classification system based on the nonparametric "Fisher-Jenks" algorithm is proposed for the estimation of meteorological drought intensity threshold levels from monthly precipitation totals. The optimized classification system is compared using the tabular accuracy index (TAI) to three fixed classification systems that are proposed in the literature and widely applied in the operational setting. An assessment of drought intensity classifications with optimized and fixed threshold levels shows that 1 ) six optimized categories most accurately divide precipitation totals into the most appropriate drought intensities, 2) optimized thresholds always give considerably improved drought intensity category allocations over fixed thresholds with the same number of categories, and 3) fixed thresholds underestimate the drought onset. An analysis of monthly and long-term drought frequency for Latin America has been conducted for assessing the spatial link between meteorological drought intensity categories computed with the Fisher-Jenks algorithm and different climate classifications. The results show a systematic match between climate variability in the region and spatial patterns of meteorological drought intensity.
\end{abstract}

\section{Introduction}

Drought originates from a temporary water deficit that results in an inability to meet the demands of human activities and the environment (Smakhtin and Schipper 2008). This deficit may be related to a lack of precipitation, soil moisture, streamflow, or any combination of the three taking place at the same time. Following Dracup et al. (1980) and Wilhite and Glantz (1985), meteorological (lack of precipitation), agricultural (decline in soil moisture), hydrological (low streamflow), and socioeconomic droughts are often distinguished. The last form may be considered a consequence of the other physically based types of drought and is associated

Corresponding author address: Paulo Barbosa, European Commission, Joint Research Centre (JRC), Institute for Environment and Sustainability (IES), Climate Risk Management Unit, Via Enrico Fermi 2749, 21027 Ispra VA, Italy.

E-mail: paulo.barbosa@jrc.ec.europa.eu with a failure of water resources systems to meet the demands for an economic activity (Wilhite and Glantz 1985; Heim 2002; Keyantash and Dracup 2002). Drought types represent different stages of the same process, reflecting the impacts on different water use sectors as a function of the timing, duration, and amount of a precipitation deficit. Thus, if one is interested in determining the cause of drought events, attention should be focused on meteorological (precipitation) drought (Dracup et al. 1980). Indeed, while the occurrence and progression of drought conditions also depend on other variables such as temperature, wind speed, evapotranspiration, and soil moisture, the precipitation deficit is the main driver of any drought event (Heim 2002; Smakhtin and Schipper 2008; Kumar et al. 2009; Vicente-Serrano et al. 2010; Mishra and Singh 2011). The longer and the more spatially extensive the lack of precipitation, the more likely different types of droughts will occur. In this paper we, therefore, concentrate on a methodology to define appropriate threshold levels for classifying precipitation 
deficits into different categories of meteorological drought intensities.

To improve drought mitigation, different indicators are used to trigger a drought response (Steinemann and Cavalcanti 2006; Goodrich and Ellis 2006). While an indicator is a derived variable for identifying and assessing different drought types, a trigger is a threshold value of the indicator used to determine the onset, intensity, or end of a drought, as well as the timing to implement proper drought response actions (Heim 2002; Vicente-Serrano et al. 2010). Since precipitation is one of the most important inputs to a watershed system and provides a direct measurement of water supply conditions over different time scales, several commonly used drought indicators rely on precipitation measurements only (Dracup et al. 1980; Heim 2002). Among them, the standardized precipitation index (SPI) of McKee et al. (1993) is certainly the most prominent and has been recommended by the World Meteorological Organization (WMO) for characterizing meteorological droughts (Svoboda et al. 2012). SPI is a statistical indicator that compares the total precipitation received at a particular location during a period of time with the long-term precipitation distribution for the same period of time at that location. To allow for the statistical comparison of wetter and drier climates, the SPI is based on a transformation of the accumulated precipitation into a standard normal variable with zero mean and variance equal to one. SPI results are given in units of standard deviation from the long-term mean of the standardized precipitation distribution. Negative values, therefore, correspond to drier periods than normal and positive values correspond to wetter periods than normal. The fundamental strength of the SPI is that it can be calculated for a variety of precipitation time scales (e.g., weekly, monthly, seasonal, or yearly accumulation periods) and updated on various time steps (e.g., daily, weekly, monthly), enabling water supply anomalies relevant to a range of end users to be readily identified and monitored. SPI is typically calculated on a monthly basis for a moving window of $n$ months, where $n$ indicates the precipitation accumulation period. For example, the SPI computed from 1-month precipitation totals (SPI-1) is mainly a meteorological drought indicator (Santos et al. 2010; Svoboda et al. 2012), while the SPI-3 (based on 3-month precipitation totals) is suitable to monitor short-term dryness in the surface layers (root zone) that are important for agricultural management (Heim 2002; Mishra and Singh 2011). Longer aggregation periods (e.g., SPI-6, SPI-12, SPI-24) are important, for example, to monitor groundwater levels and surface water supplies (Mishra et al. 2009; Mishra and Singh 2011).

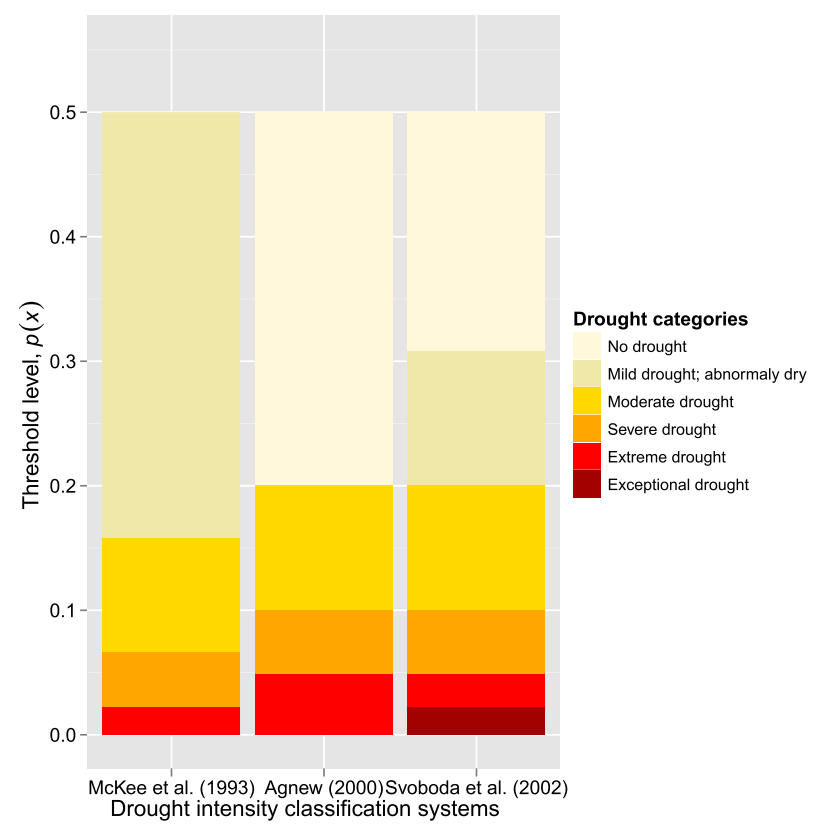

FIG. 1. Threshold levels $[\tau=p(x)]$ of drought intensity categories in different reference classification systems.

The magnitude of negative SPI values corresponds to percentiles $p(x)$ of a probability distribution that are frequently used as threshold levels (triggers) to classify meteorological drought intensity (e.g., McKee et al. 1993; Agnew 2000; Svoboda et al. 2002; Steinemann 2003). Several classification systems of meteorological drought intensity based on fixed threshold levels of the SPI have been presented in the literature. The most widely known is that proposed by McKee et al. (1993), which maps precipitation totals below the 50th percentile into four fixed categories of drought intensity (Fig. 1). For example, a "moderate" drought event starts at SPI $=-1.0$ (units of standard deviation), which corresponds to a cumulative probability of $15.9 \%$, that is, approximately the 16th percentile. McKee et al. (1993) determined that every region is in "mild" drought $34 \%$ of the time, in "moderate" drought $9.2 \%$ of the time, in "severe" drought $4.4 \%$ of the time, and in "extreme" drought $2.3 \%$ of the time (Fig. 1). The threshold levels of drought intensity proposed by McKee et al. (1993) have been used worldwide in numerous applications at different time scales of precipitation accumulation, such as to monitor drought in the United States (Hayes et al. 1999; Guttman 1999; Wu et al. 2005) and Europe (Sepulcre-Canto et al. 2012), to calculate a drought climatology for Europe (Lloyd-Hughes and Saunders 2002), for detecting droughts in East Africa (Ntale and Gan 2003), to monitor drought conditions and their uncertainty in Africa using data from the Tropical Rainfall Measuring Mission (Naumann et al. 2012), to evaluate 
the transition probabilities of drought events in the Kansabati River basin in India (Mishra et al. 2009) and in the Alentejo region in Portugal (Paulo et al. 2005), for improving the fire danger forecast in the Iberian Peninsula (Hofer et al. 2012), and to assess drought intensity in low- and high-precipitation districts of Andhra Pradesh in India (Kumar et al. 2009), to cite but a few.

Although the SPI classification system proposed by McKee et al. (1993) provides a consistent and replicable standard for drought intensity classification using threshold levels easily understood by nonexperts, its values have been questioned, for example, by Agnew (2000), Paulo et al. (2005), Kumar et al. (2009), and Quiring (2009). Indeed, Agnew (2000) proposed alternative SPI threshold levels based on fixed precipitation percentiles used by hydrologists in low flow analysis and showed that the effects of changing the threshold values is observed at the demarcation between the "mild" and "moderate" drought categories defined by McKee et al. (1993) (Fig. 1). The classification system proposed by Agnew (2000) has become widely applied during the last decade and has been used, for example, to characterize the temporal and spatial variability of droughts in Portugal between 1910 and 2004 (Santos et al. 2010), to evaluate the regional evolution of droughts in the Iberian Peninsula between 1910 and 2000 (Vicente-Serrano 2006), and to study the local pattern of droughts in the Valencia region of Spain (Vicente-Serrano et al. 2004). Drought is a more frequent phenomenon in the classification system suggested by Agnew (2000), because "extreme" droughts have an occurrence probability of $5 \%$, "severe" droughts have an occurrence probability of $10 \%$, and "moderate" droughts have an occurrence probability of $20 \%$ - "mild" drought events are classified as "no drought" and occur $30 \%$ of the time (Fig. 1).

In the context of the U.S. Drought Monitor (USDM), the SPI is one of six objective indicators (see Table 2 in Svoboda et al. 2002) that are used as a starting point in the elaboration of the weekly Drought Monitor product (Svoboda et al. 2002; Goodrich and Ellis 2006; Quiring 2009). The information from the six indicators is blended with further (local) indicators and expert knowledge from hundreds of climate and water experts across the country to derive the final drought intensity map over the United States (Svoboda et al. 2002). Because droughts are generally slow to emerge and slow to recede, the classification system defined in the Drought Monitor includes two extra SPI categories to the system proposed by Agnew (2000) at the "no drought" and "severe" intensity bounds with their respective thresholds. Svoboda et al. (2002) aim to characterize the conditions that may precede a drought or at depicting considerable impacts during a notable drought event and, therefore, suggested that "abnormally dry" conditions and "exceptional" droughts should also be considered with an occurrence probability of, respectively, $10 \%$ and 2\% (Fig. 1) - the sixth category, "no drought," above the "abnormally dry" intensity threshold level, is not shown in the Drought Monitor classification system but designates those areas not experiencing drought conditions. In the remainder of this paper, quotation marks are used to denote the drought categories as specifically defined originally by McKee et al. (1993) and expanded upon by Agnew (2000) and Svoboda et al. (2002).

Given the wide use of the SPI and the importance of the threshold levels' selection for correctly characterizing meteorological drought intensities, we propose a new methodological approach to derive such thresholds in an optimized way. The methodology is based on the FisherJenks optimal classification algorithm and the threshold levels are determined as precipitation percentiles on the basis of the empirical cumulative distribution function (ECDF) of historical precipitation totals for each season and geographic location. Our study aims to provide a blueprint for a new way to estimate the threshold levels of meteorological drought intensity classification systems with a different number of categories, even in dry climates or those with a distinct dry season where zero values are common. As a benchmark, we compare the proposed approach with the aforementioned classification systems of drought intensity based on precipitation totals and evaluate its ability for monthly and long-term drought frequency estimation. While the methodology has been tested for different accumulation periods, in this paper we present the results for 1-month accumulations only. The method is the same for other accumulation periods and the results are comparable.

\section{Data and methods}

This section describes the precipitation dataset used for validating and testing the proposed classification approach and to compare reference classification systems, the computation method of drought intensity from reference classification systems, the formulation of the Fisher-Jenks optimal approach for meteorological drought intensity classification, and the standard measure used to assess the accuracy of drought intensity classification systems.

\section{a. Precipitation data: The GPCC Full Data Reanalysis Version 6.0}

The analysis of drought intensity classification systems is performed with monthly precipitation totals from the Full Data Reanalysis Monthly Product Version 6.0 of the Global Precipitation Climatology Centre (GPCC). The GPCC was established in 1989 by request 
of WMO and provides a global gridded analysis of monthly precipitation over land from operational in situ rain gauges based on the Global Telecommunication System and historic precipitation data measured at global stations. The data supplied from 190 worldwide national weather services to the GPCC are regarded as a primary data source, comprising observed monthly totals from 10700 to more than 47000 stations since 1901. The monthly gridded datasets are spatially interpolated with a spherical adaptation of the robust Shepard's empirical weighting method (Rudolf et al. 2011).

The data used cover the whole Latin America region at $0.5^{\circ}$ latitude/longitude grid spacing (the domain of analysis is limited to land surface grid cells between $56^{\circ} \mathrm{S}$ and $35^{\circ} \mathrm{N}, 33^{\circ}$ and $120^{\circ} \mathrm{W}$ ), from January 1901 to December 2010. Latin America spans a vast range of latitudes and has a wide variety of climates. It is characterized largely by humid and tropical conditions, but important areas have been affected by "extreme" droughts in the past (e.g., Phillips et al. 2009; Sheffield et al. 2009; Zhao and Running 2010; Vargas et al. 2011) and climate change projections suggest an increased frequency of such events for the region (e.g., Magrin et al. 2007; Allen et al. 2012). Given the significant reliance of Latin American economies on agricultural production, and the exposure of agriculture to a variable climate, there is a large concern in the region about present and future climate and climate-related impacts (Trenberth and Stepaniak 2001). Latin American countries have an important percentage of their GDP in agriculture $(10 \%$ on average), and the region is a net exporter of food globally, accounting for $11 \%$ of the global value (Yadav et al. 2011). According to the agricultural statistics supplied by the United Nations Food and Agriculture Organization in 2008, $65 \%$ of the world production of corn and more than $90 \%$ of the world production of soybeans were grown in Argentina, Brazil, the United States, and China (Llano et al. 2012). The productivity of these crops is expected to decrease in the extensive plains located in middle and subtropical latitudes of Latin America (e.g., Brazil and Argentina), leading to a reduction in the worldwide productivity of cattle farming and thus adverse consequences to global food security (Magrin et al. 2007; Llano et al. 2012).

\section{b. Reference classification systems}

The classification systems of meteorological drought intensity proposed by McKee et al. (1993), Agnew (2000), and Svoboda et al. (2002), hereafter designated as the reference classification systems, are based on fixed threshold levels of the SPI and correspond to percentiles of accumulated (e.g., daily, weekly, monthly, or yearly) precipitation time series (Fig. 1). Traditionally, the classification of drought intensity based on the SPI is a three-stage process (e.g., Guttman 1999): 1) a parametric probability density function (PDF; e.g., gamma distribution) is fitted to the observed long-term accumulated precipitation recordthis is performed for each month (or whatever accumulation period) and for each geographic location; 2) once the PDF is fitted, the nonexceedance probability (or percentile) $p(x)$ of an observed precipitation amount is computed; and 3 ) the drought intensity category is determined according to one of the scales presented in Fig. 1.

Independently of the classification system used, Guttman (1999) and Ntale and Gan (2003) pointed out that different drought intensity categories will be obtained for an observed precipitation amount if different parametric probability distributions are fitted to the precipitation time series. In this context, the Weibull plotting position (Weibull 1939) has been shown to be a suitable alternative for estimating unbiased nonexceedance probabilities for any statistical distribution (Maidment 1993; Ntale and Gan 2003; Makkonen 2006). This method avoids completely the parametric distribution hypotheses and therewith the associated problems. Since this plotting-position formula only uses data ranks, it is nonparametric and has attractive properties, the most obvious being its ability to handle disproportionate outliers (Ntale and Gan 2003; Makkonen 2006). Although the Weibull plotting position has a discrete nature, it is comparable to a parametric distribution fitted to the precipitation data if the time series set is reasonably long, say about $100 \mathrm{yr}$ or more (Guttman 1999; Ntale and Gan 2003; Steinemann 2003). In this case, nonexceedance probabilities can be estimated ranging from 0.01 to 0.99 and result in a fine-resolution measure of drought intensity that covers the threshold levels $\tau=\left\{\tau_{j}: j=1, \ldots, k\right.$ categories $\}$ of the three reference systems (Fig. 1).

To classify monthly precipitation observations into reference drought intensity categories through the Weibull plotting position, the long-term records of precipitation are first converted to percentiles by developing ECDFs. In this approach, historical precipitation totals for each geographic location $g$ are stratified by month $m, 1 \leq m \leq 12$. Then, the data within the 12 monthly sets of $N$ long-term annual records are ranked from the lowest to the highest precipitation total. Estimators of the nonexceedance probabilities $p\left(x_{g, m, n}\right)$ are then calculated according to the Weibull plotting-position formula (Weibull 1939):

$$
p\left(x_{g, m, n}\right)=\frac{i_{g, m, n}}{N_{g, m}+1},
$$

where $x=$ monthly precipitation total, $g=$ geographic location, $m=$ month $(1 \leq m \leq 12), n=$ year in the time series $(1 \leq n \leq N), i=$ rank of the order statistic, and 
$N=$ number of years with monthly precipitation in the time series.

Given a monthly precipitation total $x_{g, m, n}$ whose group membership is unknown, it is mapped into reference drought intensity category $j$ if

$$
\tau_{j-1}<p\left(x_{g, m, n}\right) \leq \tau_{j},
$$

where $\tau_{j}=$ precipitation percentile corresponding to the fixed threshold level for drought intensity category $j$. The upper bound of a category is established by $\tau_{j}$ and the lower bound by $\tau_{j-1}$. Note that $\tau_{0}=0$ and $\tau_{k}=0.5$ (i.e., median of historical precipitation) for all classification systems presented in Fig. 1 , and $\tau_{j}$ represents the maximum probability of occurrence for drought intensity category $j$.

\section{c. The nonparametric classification system}

A shortcoming of the reference classification systems presented in Fig. 1 is that the drought intensity threshold levels for each category are fixed for all geographic locations and months. This standardization has been considered to be an advantage, as the deficit of precipitation can be unambiguously computed and compared over space and time (e.g., Hayes et al. 1999; Lloyd-Hughes and Saunders 2002; Vicente-Serrano et al. 2004). However, none of the fixed classification systems was specifically designed to attend the geographical variability of precipitation and its impacts on local drought conditions. For example, if the probability of zero precipitation exists, that is, $p(0)>0$, then the maximum drought intensity will be bounded by $p(0)$. Indeed, if $p(0)=0.11$, then the probability of "severe" or more intense drought conditions cannot be depicted by any of the reference classification systems (see Fig. 1), and a zero precipitation value will be categorized as a "moderate" drought event. Our solution is to empirically classify precipitation observations into homogeneous groups and identify the particular percentiles that correspond to the various drought intensity threshold levels $\tau=\left\{\tau_{j}: j=1, \ldots, k\right.$ categories $\}$ at each geographic location and time of the year.

Cluster analysis is one of a number of multivariate techniques that can be used to accomplish classification of precipitation regimes for different purposes (e.g., Guttman 1993; Gong and Richman 1995). Here, drought intensity categories (or clusters) can be defined as relative constellations of contiguous low-precipitation observations that are more similar to each other than observations in different clusters (Wilks 2005). Clustering involves the grouping of similar observations that exhibit two main properties: external isolation and internal cohesion (Cormack 1971). External isolation requires that observations within one cluster be widely separated from observations in another cluster. Internal cohesion requires that observations within the same cluster be similar to one another. Cluster analysis can be performed hierarchically or nonhierarchically. For the classification of precipitation regimes for different purposes, it has been shown that nonhierarchical methods outperform hierarchical methods (Gong and Richman 1995). In this context, the nonhierarchical Fisher-Jenks classification algorithm (Fisher 1958; Jenks and Caspall 1971) has a mathematical foundation that guarantees an optimal solution to external isolation and internal cohesion (Slocum et al. 2008). It places similar observations in the same cluster by minimizing an objective measure of classification error known as the "inertia" of the groups (Fisher 1958).

The main advantage of the Fisher-Jenks optimal algorithm over the three fixed classification systems is the ability to accommodate the temporal and geographical variations of observed precipitation amounts during the computation of drought intensity threshold levels. Because the threshold levels corresponding to different drought intensity categories are not fixed a priori, then for every time period and geographic location there is a set of threshold levels that optimize the partition of the precipitation observations into some specified $k$ number of drought intensity categories. In applying the FisherJenks optimal algorithm to meteorological drought intensity classification, we aim to estimate the drought intensity threshold levels $\hat{\tau}=\left\{\tau_{j}: j=1, \ldots, k\right.$ categories $\}$ that minimize the sum of absolute precipitation deviations about the median of drought intensity categories for each geographic location $g$ and month $m$, $1 \leq m \leq 12$, as

$$
\sum_{j=1}^{k} \sum_{n=1}^{N_{j}}\left|x_{n, j}-\tilde{x}_{j}\right|,
$$

where $N_{j}=$ total number of years with precipitation observations below the median classified in category $j$, $x_{n, j}=$ precipitation observation in category $j$ and year $n$, and $\tilde{x}_{j}=$ median of precipitation observations in category $j$. Note that, similar to the three reference classification systems, the median of historical precipitation is the best guess of unknown normal climatological precipitation conditions for each location and month. In agreement, the classification of drought intensity is based only on precipitation observations below the median.

\section{d. Accuracy assessment of meteorological drought intensity classification}

Since each classification system communicates a different concept of drought intensity and respective probability of occurrence, it is apparent that these 
concepts cannot be equally valid. The accuracy of drought intensity classification systems, that is, their ability to correctly measure the intensity of a drought event is, for example, performed on the basis of qualitative biophysical impacts on vegetation vigor or quantitative impacts on crop yield, energy production, public water supply, and other economic activities (e.g., Gouveia et al. 2009; Caccamo et al. 2011; Logar and van den Bergh 2011; Sepulcre-Canto et al. 2012; Carrão et al. 2013; Meyer et al. 2013). However, because quantitative measures of ground truth have large uncertainties associated with them and the qualitative cause-effect relationship between precipitation deficits, drought triggers and vegetation stress depends critically on associated local variables and processes of water infiltration, evaporation, transpiration, and drainage, those methods of accuracy assessment are often biased. In this paper, we use the tabular accuracy index (TAI) to assess the different classification systems of drought intensity in a statistically sound and equitable manner. TAI is a standardized measure of the disorder in the classification of numerical data, and its values are computed from the data themselves. It is computed as the ratio between the classification error and the "potential error" inherent to the unclassified data (Jenks and Caspall 1971). It was first presented by Jenks and Caspall (1971) to assess the partition of numerical and univariate cartographic observations into a number of discrete categories (e.g., Cromley and Mrozinski 1997; Armstrong et al. 2003; Traun and Loidl 2012). TAI evaluates how compact (i.e., close to each other) the data observations placed in each category of a numerical classification system are. To assess the accuracy of drought intensity classification systems under comparison in this study, for each grid cell $g$ and month $m, 1 \leq m \leq 12$, TAI is computed as follows (Jenks and Caspall 1971):

$$
\mathrm{TAI}=1-\frac{\sum_{j=1}^{k} \sum_{n=1}^{N_{j}}\left|x_{n, j}-\bar{x}_{j}\right|}{\sum_{n=1}^{N}\left|x_{n}-\bar{x}\right|}
$$

where $k=$ number of drought intensity categories, $N=$ number of years with precipitation observations below the median, $N_{j}=$ number of years with precipitation observations below the median in class $j, x_{n}=$ precipitation observation in year $n, x_{n, j}=$ precipitation observation in category $j$ and year $n, \bar{x}_{j}=$ mean of precipitation observations in category $j$, and $\bar{x}=$ mean of all precipitation observations.

TAI values range from 0 to 1 , with 0 representing the lowest accuracy and 1 representing the highest accuracy. A TAI value of 0 will result only when no grouping (i.e., one class) has been applied to the data observations; a TAI value of 1 occurs only when the values of data observations in each category are identical (i.e., the variance is zero within each class). For example, a six-class system can only achieve a TAI value of 1 if there are exactly six distinct values in a numerical sample of observations.

The GPCC grid cells that for a given month have fewer than five nonzero historical precipitation records below the median are not used for the accuracy assessment of drought intensity classification systems on that month, the reason being that the number of distinct precipitation records is insufficient to estimate the drought intensity threshold levels $\tau_{j}$ for the six-class classification systems and to compute the respective TAI values. The removal of these grid cells ensures that the accuracy assessment of all classification systems is based on the same sample set and comparisons between TAI values are statistically sound for each month.

\section{Results and discussion}

In this section, we present a comparison between the reference classification systems of meteorological drought intensities proposed by McKee et al. (1993), Agnew (2000), and Svoboda et al. (2002) for SPI, their comparison with the optimized classification of drought intensities derived with the Fisher-Jenks classification algorithm, and the individual analysis of the optimized thresholds for different clustering configurations.

\section{a. The optimization of drought intensity categories with the Fisher-Jenks algorithm}

In the case of clustering the GPCC precipitation data into two drought categories, the single optimized threshold $\hat{\tau}_{2}$ divides between the sample observations that are closer to the observed minimum historical precipitation value and those that are closer to the estimated median precipitation value for that geographic location. Since the minimum historical precipitation value represents the driest conditions observed for that location and the estimated median represents the respective expected normal climatological conditions, then the two categories that are identified in the data can be conceptually nominated as drought and nondrought. The estimated threshold level $\hat{\tau}_{2}$ conceivably represents the precipitation percentile that optimally divides the precipitation observations into those two conditions and marks the effective onset of a meteorological drought at this level of generalization. If the precipitation data below the median are uniformly distributed, then the single optimized threshold $\hat{\tau}_{2}$ allocates the same number of observations in the drought and nondrought categories. However, it is often the case that no clear uniform structure is observed 
(a)

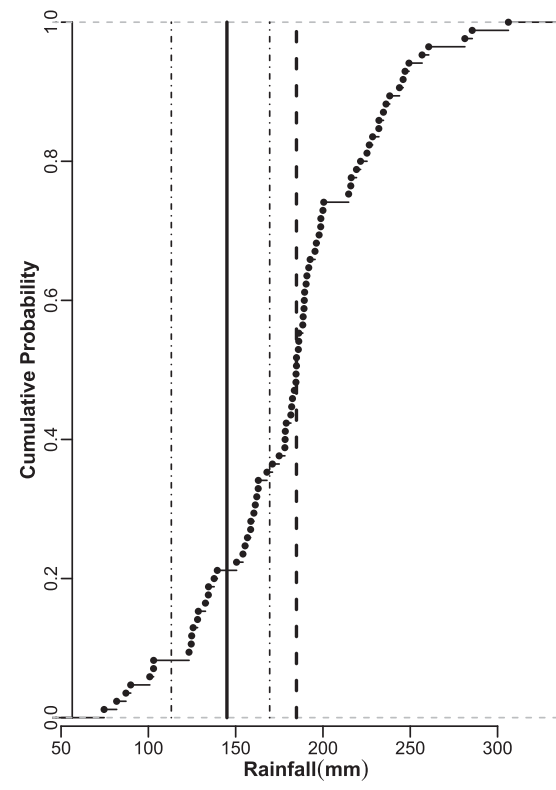

(b)

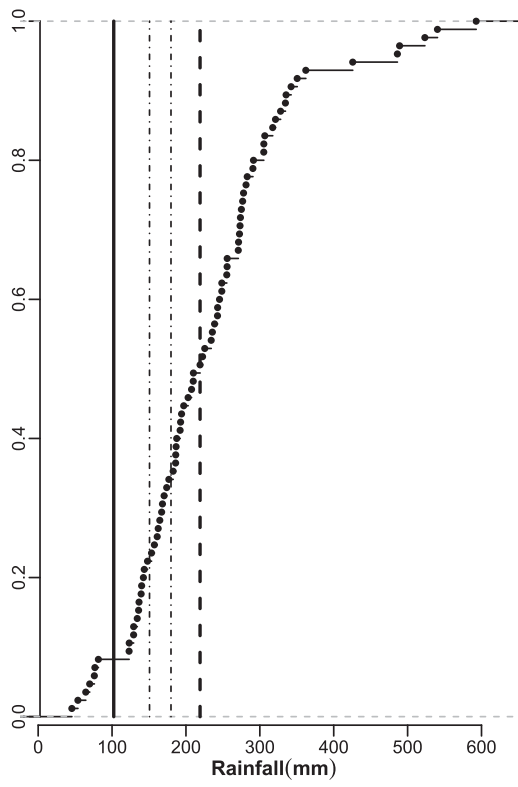

(c)

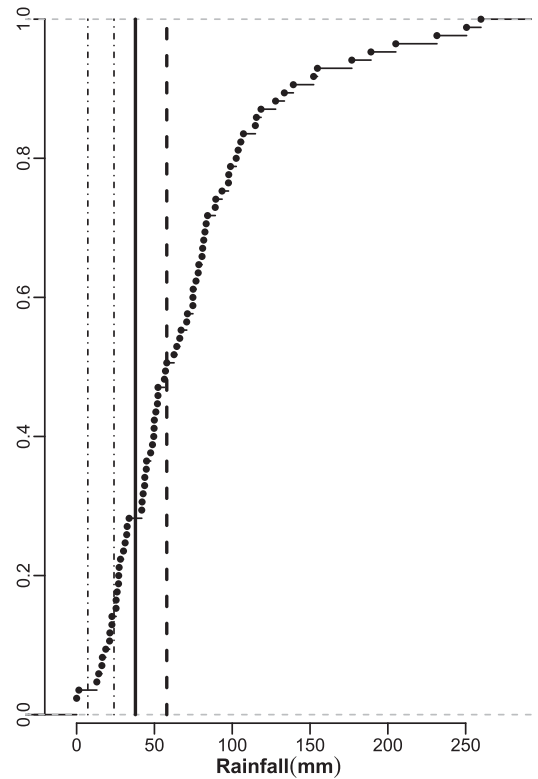

FIG. 2. Drought intensity threshold levels $\tau$ estimated for grid cells with different empirical cumulative distribution functions (dashed line-median; thick solid line-threshold level optimized with two clusters; dot-dashed lines—-threshold levels optimized with four clusters). (a) Distribution below the median approximately uniform; (b),(c) distribution below the median with isolated observations in the left and right bounds, respectively.

in the data, and the positioning of the optimized threshold level $\hat{\tau}_{2}$ depends on the shape of the left tail of the ECDF fitted to the whole precipitation time series.

An analysis of the GPCC data reveals that three typical situations represent the optimized partition of the ordered precipitation time series below the median into two generalized drought categories (Fig. 2): in Fig 2a, the precipitation distribution is free of "isolated" groups of observations near its minimum or median values, and the two-class threshold is a robust and resistant measure of central partition that optimally discriminates between drought and nondrought events for the location in a given month; in Fig $2 b$, the precipitation distribution has a disrupted single set of low-precipitation records isolated in the left tail, and the two-class threshold discriminates these "extreme" drought intensity events for the location; in Fig 2c, the precipitation distribution has a disrupted single set of isolated precipitation records near the median, and the two-class threshold discriminates these "moderate" drought intensity events for the location.

To avoid the semantic complexity in the drought intensity classification of samples represented by Figs. 2b,c, the number of categories can be increased. When a classification system with four categories (i.e., "extreme," "severe," "moderate," and "no drought") is used to group the precipitation data, the positioning of the two additional threshold levels depends on the percentile rank of the single threshold level $\hat{\tau}_{2}$, as shown in Fig. 2. Statistical analysis of the cases introduced in Fig. 2 reveals that $97.8 \pm 1.2 \%(p<0.05)$ of the geographical points in the study area match the category in Fig. 2 a each month. Consequently, the "severe" drought threshold level in the four-class drought intensity system can be used as a generalized onset boundary that divides between effective drought and nondrought states for the region, while the two extra thresholds are further used to identify particular regimes within those two states, namely nearnormal and extremely low-precipitation conditions. Moreover, the optimized four-class system reduces the bias in the positioning of the generalized two-class threshold level according to the arrangement of extreme observations and eases the operational monitoring of drought by better depicting the evolution of its conditions through the inclusion of more drought intensity categories. The ability for improved monitoring of meteorological drought conditions can be further enhanced with the use of a six-class drought system (i.e., "exceptional," "extreme," "severe," "moderate," "abnormally dry," and "no drought"). In this case, the "extreme" and "moderate" drought intensity threshold levels move toward the "severe" drought threshold to find the optimal positioning in the new system. The two new threshold levels are added with the designations of "abnormally dry" and "exceptional" drought to identify limit precipitation conditions for the region. 
(a)

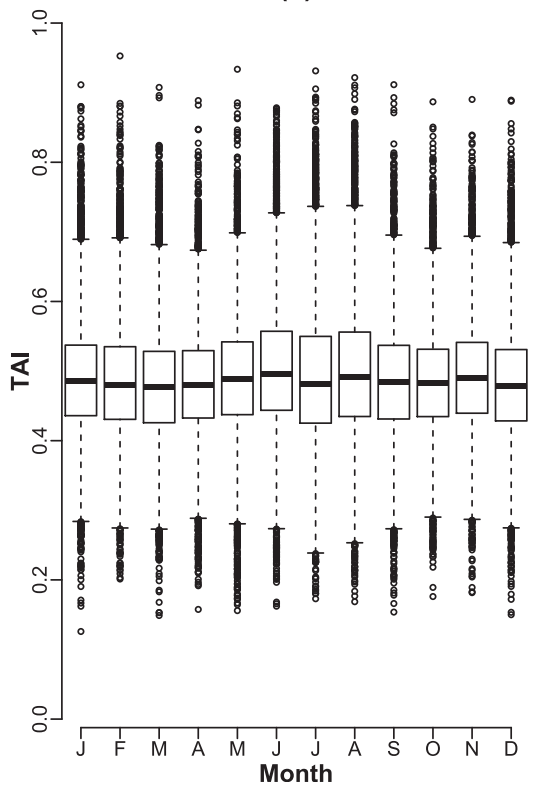

(b)

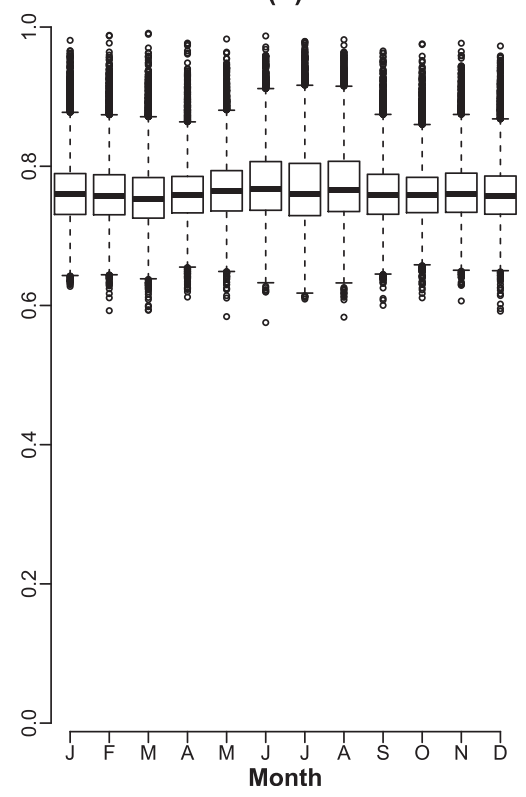

(c)

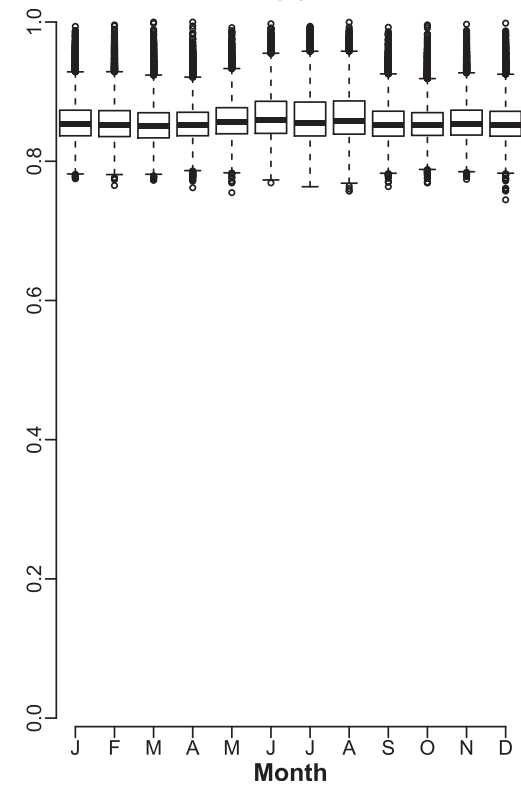

FIG. 3. Frequency box-plot distributions of monthly overall accuracy (as measured by TAI): (a) clustering with two drought categories; (b) clustering with four drought categories; (c) clustering with six drought categories. The number of GPCC precipitation grid cells for each month $>8000$.

Figure 3 shows the monthly frequency distributions of TAI in the study area for the classification of precipitation data in two, four, and six drought clusters. It can be seen from the monthly frequency distributions that the rate of improvement in the classification accuracy has an exponential behavior and decreases beyond four drought categories (i.e., "extreme," "severe," "moderate," and "no drought"). Indeed, there is an average monthly gain in the classification accuracy of $60 \%$ from two to four clusters, but only of $10 \%$ from four to six clusters. Given that $98.7 \pm 0.4 \%(p<0.05)$ of the geographic points in the study area attained more than $80 \%$ TAI per month with the six-class drought system, we are confident that the use of six optimized groups to classify precipitation observations into drought intensities is sufficient for the study area and precipitation data used.

\section{b. Comparison of reference classification systems}

Figure 4a summarizes the differences between the mean monthly overall accuracy (as measured by the TAI) attained with the reference classification systems for the whole study area. The results give an estimate of the accuracy gain from the first to the second classification system. The comparison between the reference systems with four drought intensity categories (Fig. 1), that is, McKee et al. (1993) and Agnew (2000), reveals that the former performs significantly worse $(p<0.01$, Fig. 4a) than the latter in the study area, with approximately 0.05 lower TAI per month. A comparison with Fig. 1 shows that the accuracy gain with the classification system proposed by Agnew (2000) is due to an increase of all of the precipitation percentiles used as threshold levels to distinguish between drought intensity categories. Overall, the results support the adjustments made by Agnew (2000) to the classification system proposed by McKee et al. (1993) and indicate that the natural grouping of precipitation observations within a fourclass drought intensity system for the study area is better performed by using threshold levels that correspond to percentiles higher than those suggested by McKee et al. (1993). From an operational viewpoint, this aspect has an important impact as it implies that the threshold levels for the drought intensity categories proposed by McKee et al. (1993) are likely to underestimate on average the onset percentile and probability of occurrence of meteorological drought events within different intensity categories.

As expected, the experiments also show that the sixclass drought intensity classification system proposed by Svoboda et al. (2002) (Fig. 1) performs significantly better $(p<0.01$; Fig. $4 \mathrm{a})$ than the four-class drought intensity classification system introduced by Agnew (2000) (Fig. 1) -almost 0.15 TAI on average per month in the study area. Since the threshold levels of drought intensity categories with analogous semantic definitions in both classification systems match, that is, "moderate," "severe," and "extreme" drought categories have boundaries that correspond to the same precipitation percentiles 
(a)

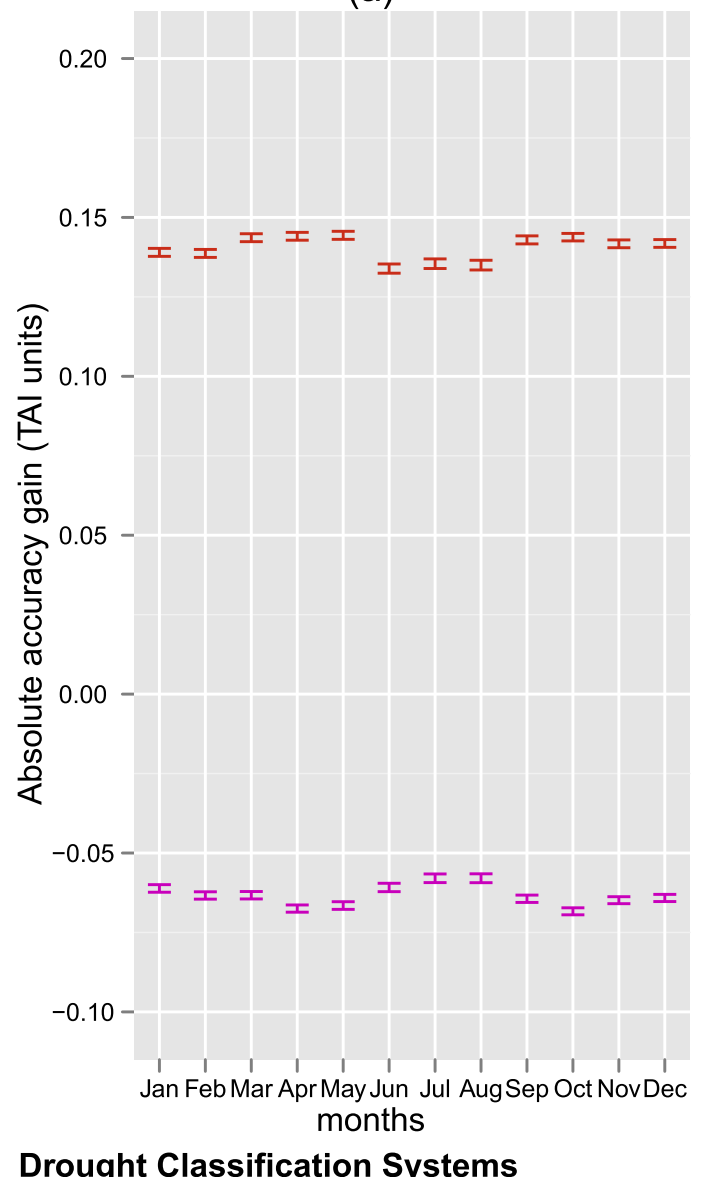

Drought Classification Systems

— (4c) McKee et al. (1993) - (4c) Agnew (2000)

- (6c) Svoboda et al. (2002) - (4c) Agnew (2000) (b)

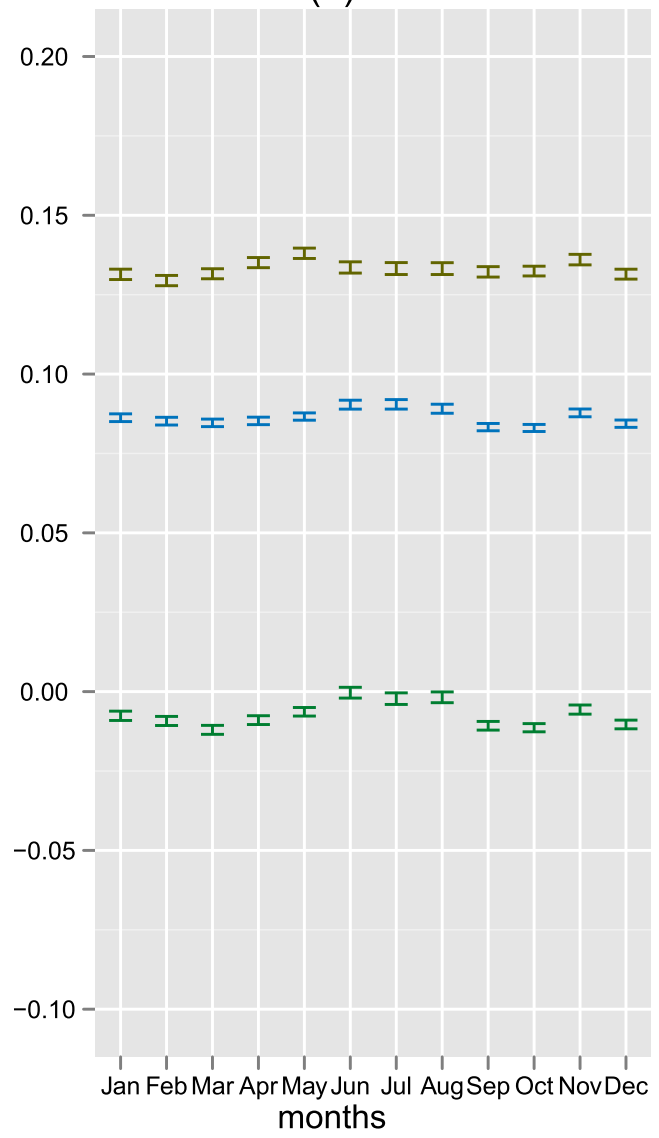

Drought Classification Systems

- (4c) Fisher-Jenks - (4c) Agnew (2000)
- (4c) Fisher-Jenks - (6c) Svoboda et al. (2002)
- (6c) Fisher-Jenks - (6c) Svoboda et al. (2002)

FIG. 4. Difference of the mean monthly overall accuracy (as measured by TAI) between drought intensity classification systems (4c-classification system with four drought intensity categories; $6 \mathrm{c}$-classification system with six drought intensity categories): (a) comparison between reference fixed threshold systems; (b) comparison between the classification performed with the Fisher-Jenks algorithm and the reference systems. The $99 \%$ confidence intervals are indicated on each bar. The number of GPCC precipitation grid cells for each month $>8000$.

(Fig. 1), it can be argued that the inclusion of two extra categories in the system proposed by Svoboda et al. (2002) at the lower and higher ranks of the precipitation distribution provides a more coherent categorization of sample observations. Although the two additional drought categories are responsible for an overall enhancement of the classification accuracy, we acknowledge that the fact that these categories provide preciseness on the estimated onset frequency of drought events (by means of the new class "abnormally dry") and discrimination between "exceptional" and "extreme" drought events is more important. We are of the opinion that the gain in the mean monthly overall classification accuracy justifies the inclusion of these two extra drought intensity categories, as from the operational viewpoint they help the user to better understand the drought process during its early and ultimate stages, when compared to the reference four-class drought classification systems.

\section{c. Comparison between reference and optimized classification systems}

Figure $4 \mathrm{~b}$ shows the differences between the mean monthly overall accuracy of drought intensity classifications performed with the Fisher-Jenks classification algorithm and the reference classification systems proposed by Agnew (2000) and Svoboda et al. (2002). The geographic distributions of the classification accuracy 

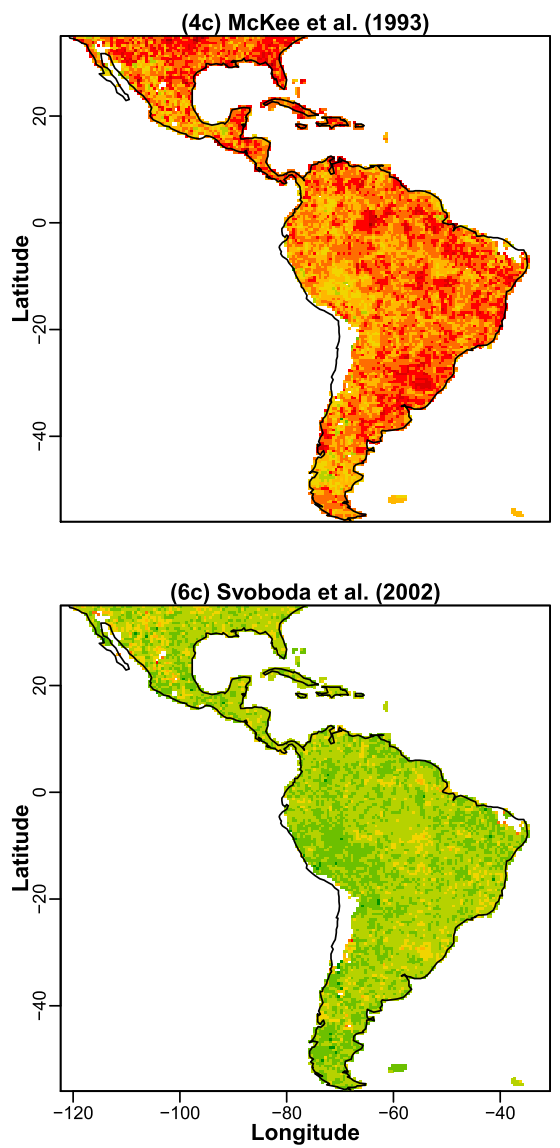
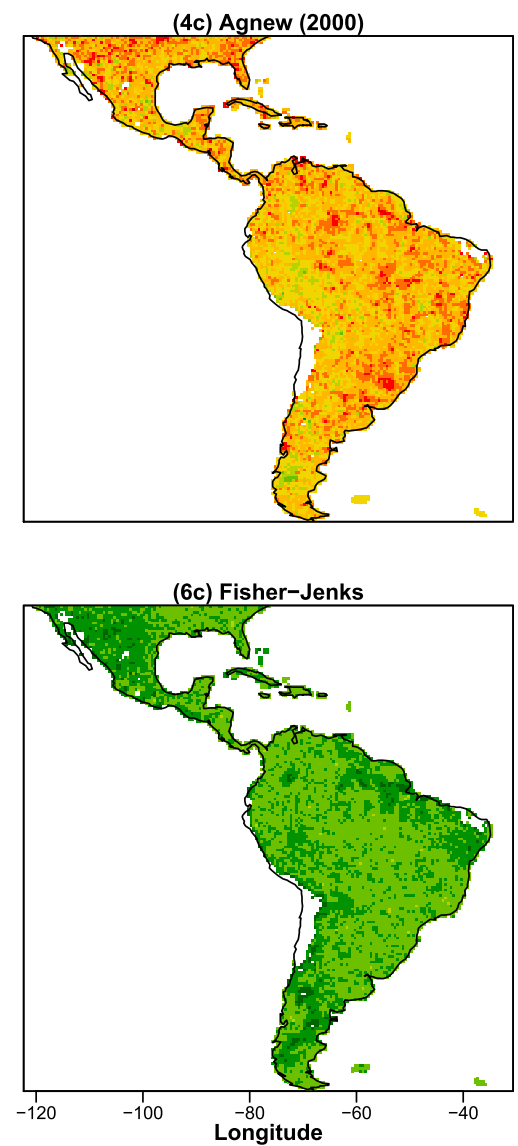

(4c) Fisher-Jenks
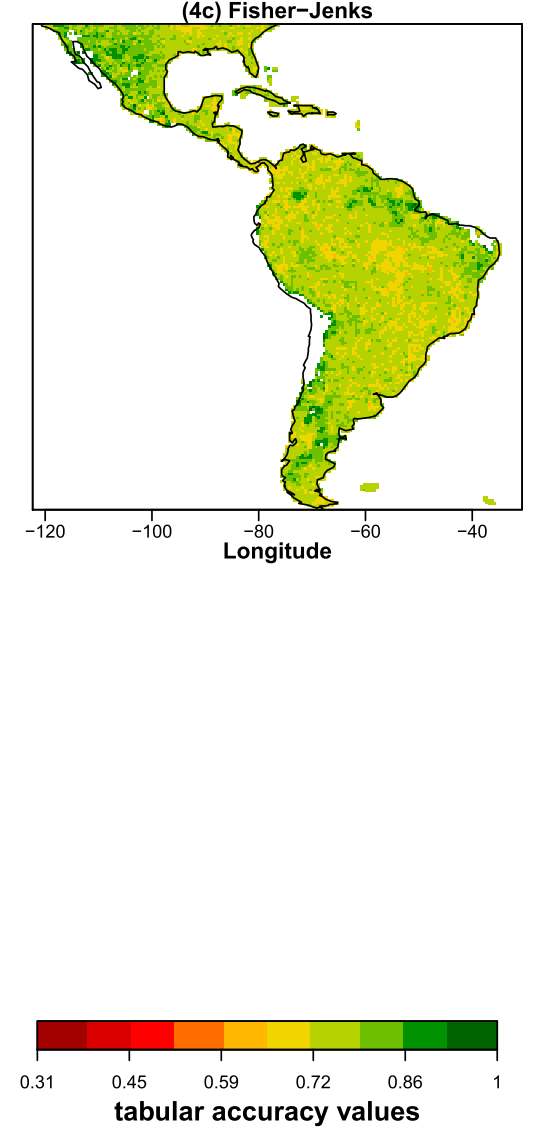

FIG. 5. Geographic distribution of overall classification accuracy (as measured by TAI) in November for different classification systems. Grid cells with $<5$ nonzero historical precipitation records below the median are masked out in white.

for November in the study area are illustrated for all reference and optimized systems in Fig. 5. As a general pattern, it is shown in Figs. $4 \mathrm{~b}$ and 5 that the accuracy of the classifications performed with the Fisher-Jenks algorithm is always significantly higher $(p<0.01$; Fig. $4 \mathrm{~b})$ than those performed with the reference classification systems when the optimal clustering is performed with the same number of categories. It is interesting to note that the classification system optimized with four drought clusters ("extreme," "severe," "moderate," and "no drought/mild drought") has a mean monthly overall accuracy gain of almost 0.15 TAI relative to the reference system proposed by Agnew (2000), that is, $0.20 \mathrm{TAI}$ on average above the scores obtained with the classification system proposed by McKee et al. (1993). Similarly, and to strengthen the advantages of the proposed classification approach, it is also shown that the six optimized drought groups ("exceptional," "extreme," "severe," "moderate," "abnormally dry," and "no drought") have an accuracy gain of approximately $0.10 \mathrm{TAI}$ in the study area relative to the classification system of Svoboda et al. (2002). A smaller improvement in the accuracy is achieved because the two additional categories in the system proposed by Svoboda et al. (2002) already convey a within-class variability that is smaller than that of the system proposed by Agnew (2000). Nonetheless, by optimizing the threshold levels for distinguishing between four categories of drought intensity, an accuracy gain that is remarkably similar to that of the system proposed by Svoboda et al. (2002) is obtained (Figs. 4b and 5). Indeed, the mean accuracy differences between the four optimized categories and the Svoboda et al. (2002) classification system are significant ( $p<0.01$; Fig. 4b) for some months, but only slightly inferior $(<0.01 \mathrm{TAI}$ on average $)$. This shows that the information on drought intensity provided by the four optimized clusters can be as accurate as that provided by the six-class reference system that is not optimized - there are more categories but almost no gain in the allocation of the individuals in the most appropriate drought intensity group.

Overall, the results presented in Figs. 4 and 5 show that there is a specific set of threshold levels that optimize the grouping of precipitation data within a particular 
number of drought intensity categories for each month and geographic location. The optimized grouping can be obtained by tuning the positioning of the class boundaries with respect to a numerical minimization of classification error, as provided in Eq. (2). Indeed, our tests reveal that neither the classification system proposed by Agnew (2000) nor that proposed by Svoboda et al. (2002) can effectively depict the precipitation percentiles conveying local partitions that maximize the cohesion of individuals within the drought intensity groups effectively created. On the other hand, the Fisher-Jenks classification provides an improvement over choosing a fixed partition of the feature space for defining threshold levels of drought intensity.

\section{d. Evaluation of optimized threshold levels}

Let us finally compare the precipitation percentiles corresponding to the optimized drought intensity threshold levels $\tau=\left\{\tau_{j}: j=1, \ldots, k\right.$ categories $\}$ with the equivalent boundaries in the reference classification systems (as presented in Fig. 1). Figure 6 presents the empirical PDFs of the drought intensity threshold levels $\tau$ optimized with four and six clusters in the study area for representative months of different seasons. Although the PDFs converge asymptotically to the empirical modes presented in Table 1, it is also true that the variance of the optimized threshold levels is effectively too large to use fixed thresholds. Naturally, this implies that the threshold levels for splitting drought intensity categories are better estimated on the basis of individual characteristics of precipitation distribution along the number line than on fixed boundaries for each geographic location. It is confirmed from the results detailed in Fig. 6 that a classification system with a priori defined and fixed threshold levels cannot split precipitation observations into drought intensity categories with the same accuracy in space and time.

The main concern with the reference classification systems is that the threshold levels underestimate on average the onset of mid-intensity drought events. For example, the probability of occurrence of "severe" drought is defined in Agnew (2000) and Svoboda et al. (2002) by a fixed precipitation percentile of approximately 0.1 (Fig. 1). In opposition, the empirical PDFs from Fig. 6 and modes presented in Table 1 indicate that the expected probability of occurrence of this type of drought event is around 0.2 for all months and optimized classifications systems with four and six clusters. From an operational viewpoint, this finding is relevant as it suggests that drought events occur more frequently than estimated by the reference classification systems and it can be responsible for delayed mitigation actions. Moreover, for our study area, the classification system (a)

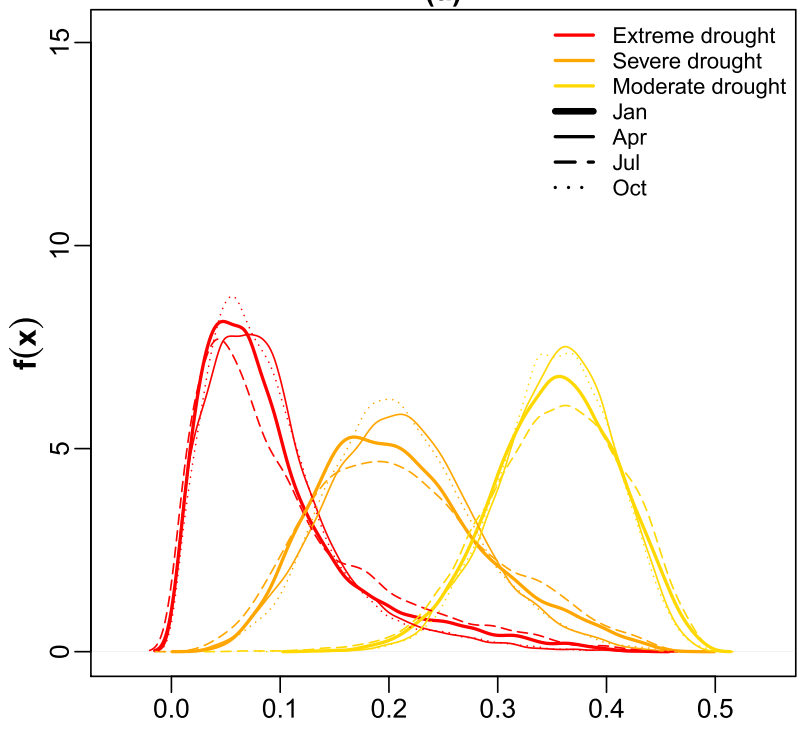

(b)

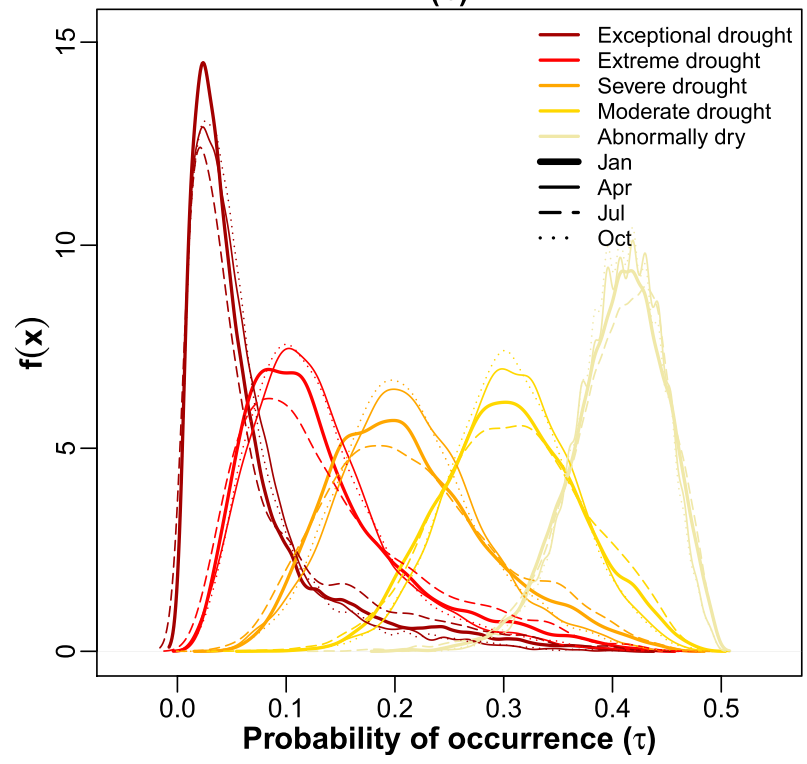

FIG. 6. Empirical PDFs of drought intensity threshold levels $\tau$ in the study area for January, April, July, and October: (a) clustering optimized with four drought categories; (b) clustering optimized with six drought categories. The number of GPCC precipitation grid cells to compute each PDF $>8000$.

proposed by McKee et al. (1993) underestimates the threshold levels for all categories, that is, it is based on precipitation percentiles that are on average lower than the optimal boundaries empirically determined for the respective drought intensity categories. These results are in agreement with the findings of earlier studies in different geographic locations. For example, Kumar et al. (2009) used monthly precipitation data to evaluate the response of the drought intensity categories proposed by 
TABLE 1. Empirical modes estimated for the PDFs of percentile threshold levels $\tau=\left\{\tau_{j}: j=1, \ldots, k\right.$ categories $\}$ presented in Fig. 6 . The number of GPCC precipitation grid cells for each month $>8000$.

\begin{tabular}{|c|c|c|c|c|c|c|c|c|}
\hline \multirow[b]{2}{*}{ Drought categories } & \multicolumn{4}{|c|}{ Four drought categories } & \multicolumn{4}{|c|}{ Six drought categories } \\
\hline & Jan & Apr & Jul & Nov & Jan & Apr & Jul & Nov \\
\hline "Exceptional" drought & - & - & - & - & 0.03 & 0.03 & 0.03 & 0.03 \\
\hline "Extreme" drought & 0.06 & 0.07 & 0.06 & 0.06 & 0.10 & 0.11 & 0.11 & 0.11 \\
\hline "Severe" drought & 0.19 & 0.20 & 0.19 & 0.20 & 0.22 & 0.21 & 0.21 & 0.20 \\
\hline "Moderate" drought & 0.36 & 0.36 & 0.36 & 0.36 & 0.31 & 0.32 & 0.31 & 0.32 \\
\hline "Abnormally dry" & - & - & - & - & 0.41 & 0.41 & 0.42 & 0.41 \\
\hline
\end{tabular}

McKee et al. (1993) to drought in India. Their results indicate that the classification system of McKee et al. (1993) underestimates the drought intensity in their study area. Indeed, "moderate" drought intensity was depicted when low-precipitation values were representative of "extreme" drought events for the region. Similarly, Morid et al. (2006) showed that the classification system proposed by McKee et al. (1993) responds slowly to drought onset in Iran and that the categories tend to reduce the drought intensity of dryness in the region. Paulo et al. (2005) found that the analytical steady probabilities of the "moderate" drought category in the Alentejo region in Portugal are higher than those presented by McKee et al. (1993) and around the 36th precipitation percentile, in agreement with our findings for Latin America presented in Table 1. In accordance, Quiring (2009) found that the thresholds proposed by McKee et al. (1993) underestimate the severity of drought conditions in Texas and the drought responses would not be triggered early enough if they were used operationally.

Nevertheless, it is important to highlight that the modes of the empirical PDFs for the precipitation percentiles corresponding to the optimized threshold levels of "exceptional" and "extreme" drought categories (Fig. 6 and Table 1) are comparable to, respectively, the Svoboda et al. (2002) and Agnew (2000) reference classification systems in all months: around the 5th precipitation percentile as suggested by Agnew (2000) and around the 2nd percentile as suggested by Svoboda et al. (2002). This outcome is extremely relevant as it clearly indicates that both reference systems are providing information about the maximum drought intensity that is consistent with the maximum probability of occurrence estimated with the empirical PDFs for the study area. Thus, it implies that for most geographical locations the users of such systems are generally well informed about the occurrence of "extreme" and/or "exceptional" drought conditions in the study area.

\section{Drought frequency analysis}

The potential applications of the proposed classification approach are numerous and varied. In this paper, we present a case study on the optimized estimation of meteorological drought intensity threshold levels for adaptive drought frequency computation. When the concept of frequency is applied to drought-related variables, it indicates the number of times that a drought intensity class is triggered in a given geographic location over a period of time (Steinemann 2003; Steinemann and Cavalcanti 2006). On a monthly basis, the drought frequency for intensity category $j=1, \ldots, k$ categories is simply the precipitation percentile corresponding to the optimized $\tau_{j}$. Although monthly drought frequencies are already important for preparedness and mitigation of impacts on particular sectors of activity, such as seasonal rain-fed agriculture, they can further be extended to depict the long-term drought frequency for each geographic location. Indeed, long-term drought frequencies can be used to better understand the overall hydrological system in a basin and help with taking precautionary measures on drought. For example, long-term drought frequency is important to manage the hydropower production in a reservoir and the water supply capacity to satisfy the municipal consumption (Dracup et al. 1980; Panu and Sharma 2002; Mishra et al. 2009). In the long term, the frequency of drought category $j$ is independent of the initial monthly $\tau_{j}$ (Paulo et al. 2005). Then, the long-term frequency $\pi_{j}$, also referred to as the steadystate probability (Steinemann 2003; Paulo et al. 2005), can be characterized by a first-order Markov chain and is given by (Wilks 2005)

$$
\pi_{j, g}=\frac{p_{01, g}}{1+p_{01, g}-p_{11, g}}
$$

where $j=1, \ldots, k$ drought intensity categories, $g=$ geographic location, $p_{01}=P\left\{\tau_{n+1} \leq j \mid \tau_{n}>j\right\} \forall j=1, \ldots, k$, $n \in N, p_{11}=P\left\{\tau_{n+1} \leq j \mid \tau_{n} \leq j\right\} \forall j=1, \ldots, k, n \in N$, and $N=$ total number of months in the precipitation time series. The maximum likelihood estimators (MLEs) of $p_{01}$ and $p_{11}$ are simply computed from the number of monthly transitions between the respective drought categories during the analysis period as, for example, 


$$
p_{01}=n_{01} / n_{0},
$$

where $n_{01}$ is the number of monthly transitions between $\tau_{n}>j$ and $\tau_{n+1} \leq j$, and $n_{0}$ is the total number of monthly transitions between $\tau_{n}>j$ and another data point in the time series.

Figure 7 shows the geographic distribution of the precipitation percentiles corresponding to the optimized threshold levels $\tau_{j}$ (i.e., monthly frequency) of "moderate," "severe," and "extreme" drought from a four-class system. The months depicted are representative of different seasons and the maps displayed for the study area are informative in several ways. It can be seen that there is a spatial variation of the frequency for each season and drought intensity class, indicating that there is a unique percentile threshold that depends on the specific climatological characteristics of the geographic location in that month. Because of their standardization and the fixed thresholds, the reference classification systems cannot depict this geographic and temporal variability in the meteorological drought frequency, because all locations will have the same frequency at a given drought intensity category for all months.

The results of long-term drought frequency $(\pi)$ estimated with the two-class threshold level and the "severe" drought intensity threshold levels of both four- and six-class classification systems are compared in Fig. 8. We have obtained corresponding spatial patterns in the three maps, demonstrating that there is a match between the generalized two-class threshold level and the intermediate drought intensity threshold levels of "severe" drought in the four- and six-class systems. This outcome supports the hypothesis that this mid-drought intensity threshold is a transverse and robust benchmark that can be used as a reference for detecting the effective drought onset in any of the optimized classification systems. Indeed, Figs. 8a-c consistently show a match between the geographic pattern of "severe" meteorological drought frequency in Latin America and the wide variety of regional climates, as depicted by the world map of Köppen-Geiger (Kottek et al. 2006): the arid regions of northeastern Brazil, central-western and southeastern Argentina, and north-central Mexico are more subject to frequent monthly droughts, whereas the areas with lower probability of occurrence of meteorological drought are located in the equatorial fully humid areas of northwestern Amazonia, along the respective coastlines of Peru and Ecuador, and in the warm temperate climates of southern Chile and southeastern Brazil.

The additional threshold levels located above or below the precipitation percentile that corresponds to the mid-drought intensity boundary in any of the optimized classification systems show the transitions between different phases of the drought process that can be of interest during the preparedness phase of risk management. For example, Fig. 9 shows the spatial distribution of the long-term drought $(\pi)$ threshold levels optimized for the six-class drought intensity system. The maps indicate that the whole eastern and northeastern region of Brazil has the same probability of occurrence of an "abnormally dry" event. However, the geographical patterns of the threshold levels of more intense drought categories change for that region and can be further depicted in Figs. 9b-e. Indeed, although the whole geographical region is subject to the same frequency of "abnormally dry" events (Fig. 9a), there is an evident variation on the geographical distribution of frequencies at the level of "exceptional" drought (Fig. 9e). At this ultimate drought intensity level, the higher frequency is located in a smaller area at the northeast and is distinct from the rest of the region. These singularities in the geographic distribution of drought frequency at different drought intensities are due to monthly variations of threshold levels within the same drought intensity class at each geographic location and cannot be flexibly depicted from the reference classification systems.

\section{Conclusions}

As pointed out throughout this paper, there is a need to improve the positioning of meteorological drought intensity threshold levels based on precipitation percentiles, since a misrepresentation leads to a bias in the estimation of drought intensity categories based on precipitation amounts. Thus, the main objective of this work was to formulate, validate, and test an approach for the optimized classification of meteorological drought intensity threshold levels from precipitation data that can better represent the frequency of occurrence and the intensity of this complex hazard in space and time. As a benchmark, we compare it with some of the reference classification systems commonly presented in drought literature and used operationally.

The use of the Fisher-Jenks classification algorithm was found to accurately estimate the threshold levels that better depict the spatial and temporal variably of meteorological drought intensity in regions with different climate conditions, including those with a distinct dry season where zero values are common. Using an independent approach for determining meteorological drought intensity ensures that variations in climate are correctly accounted for so that its frequency is accurately computed. The goal of the method is to develop an ordinal classification of precipitation, based entirely on the positioning of observations along the number 

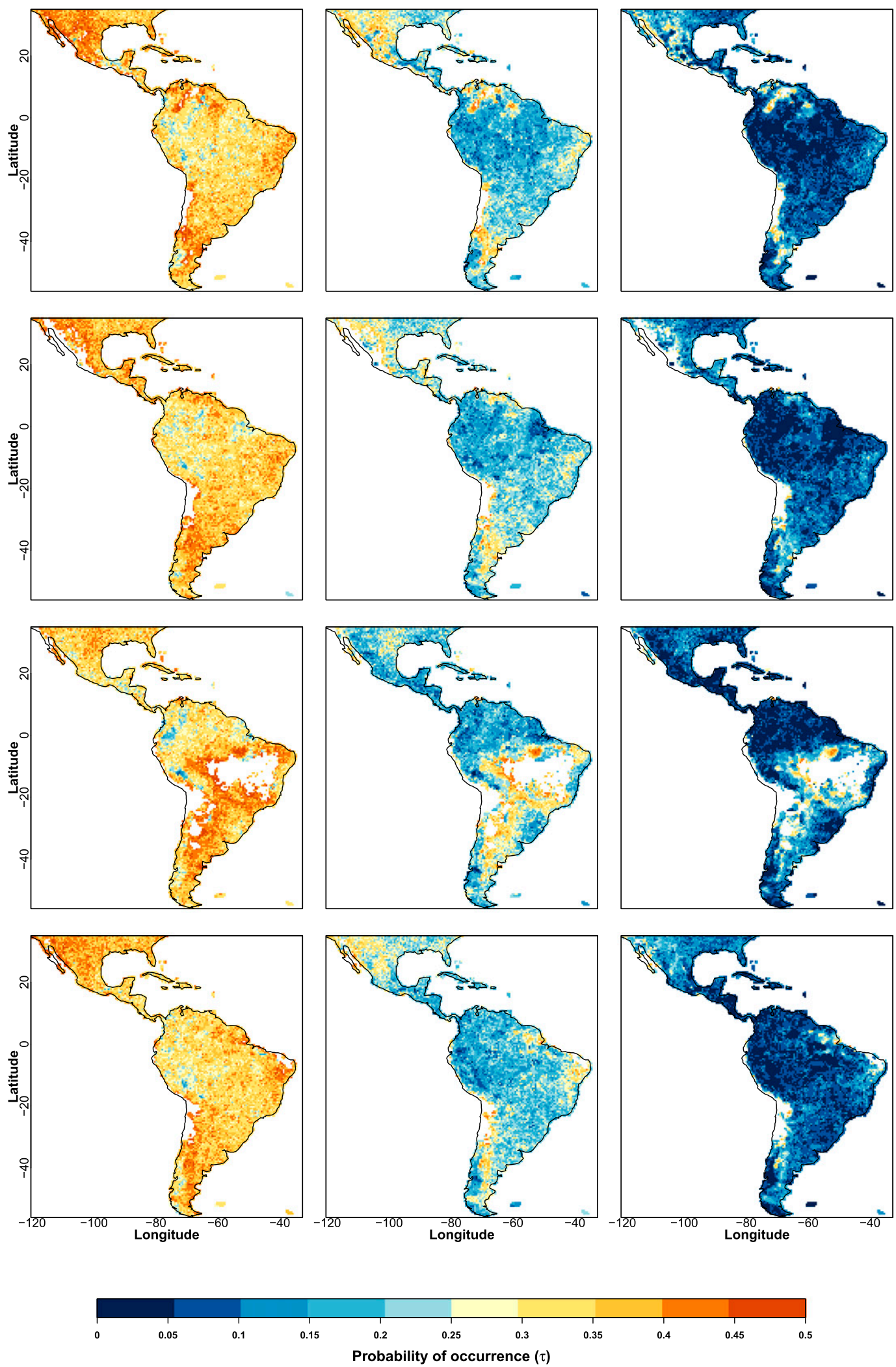

FIG. 7. Probability of occurrence $(\tau)$ of (left) "moderate," (center) "severe," and (right) "extreme" drought intensities for (top) January, (top middle) April, (bottom middle) July, and (bottom) October. Grid cells with $<5$ nonzero historical precipitation records below the median are masked out in white. 

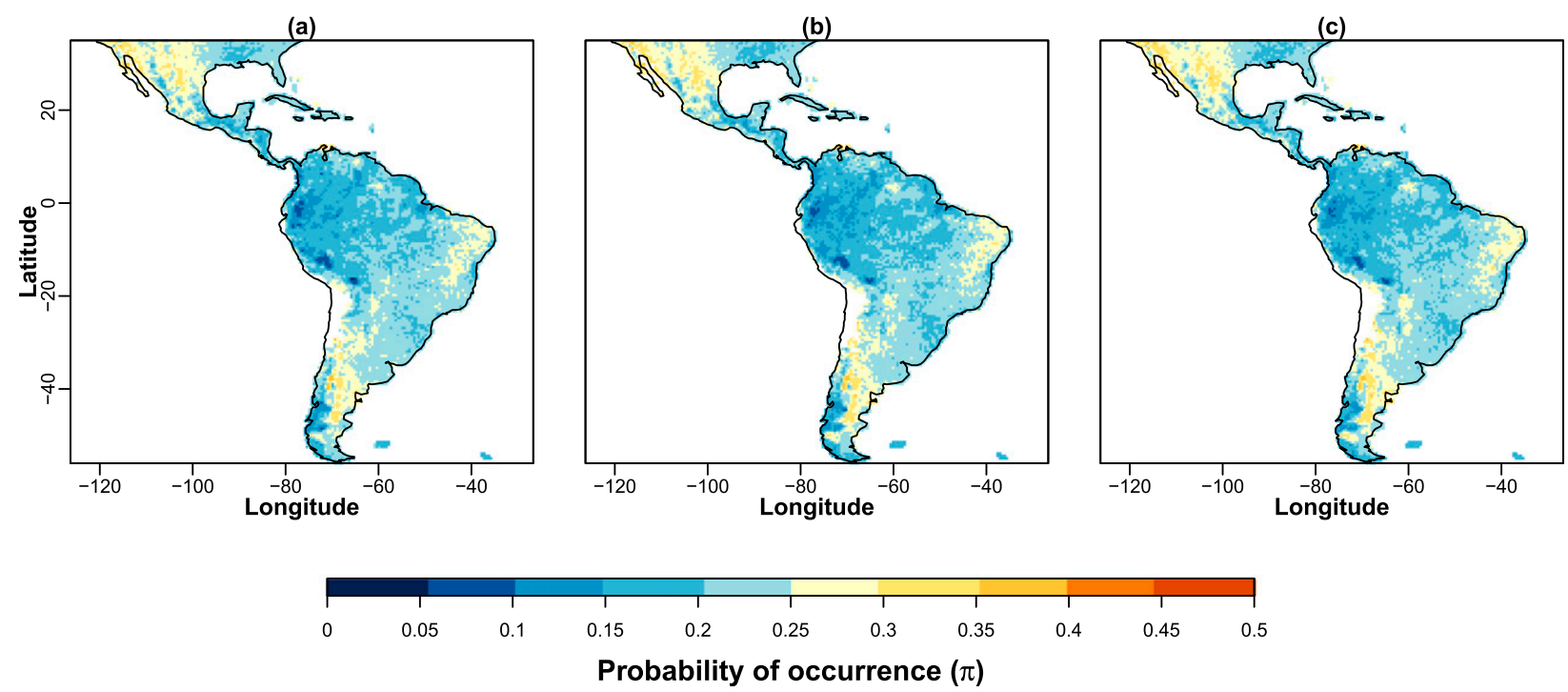

FIG. 8. Long-term probability $(\pi)$ of "severe" drought occurrence for different classification systems: (a) two drought categories; (b) four drought categories; (c) six drought categories. Grid cells with $<5$ nonzero historical precipitation records below the median are masked out in white.

line, in which total within-class variance is minimized. To evaluate the goodness-of-fit of the classification approach, we used a statistical measure, namely the tabular accuracy index. Classification results over Latin America indicate that two optimized drought categories cannot completely identify the meteorological drought onset for all seasons and geographic locations, because the classification is affected by the values in the tails of the precipitation distribution. However, by increasing the number of optimized categories, this limitation is amended and a six-class drought intensity classification system was shown to accurately allocate the monthly precipitation observations into the most suitable meteorological drought intensity category for all cases.

The comparison between the "optimal" system and three reference drought systems, namely those proposed by McKee et al. (1993), Agnew (2000), and Svoboda et al. (2002), shows that the optimized thresholds significantly improve the overall accuracy of meteorological drought intensity classification as compared to the fixed thresholds. The analysis of drought intensity classification systems was performed with monthly precipitation totals from the Full Data Reanalysis Monthly Product Version 6.0 of the Global Precipitation Climatology Centre. Although there is some inevitable smoothing of the precipitation time series in interpolating observations to a grid, tests at individual stations with complete data records resulted in the same conclusion. The accuracy attained with the six-class optimal system is on average 0.10 TAI superior to that attained with the Svoboda et al. (2002) system, and the four-class optimal system is $0.15-0.20$ TAI greater than, respectively, those attained with the Agnew (2000) and McKee et al. (1993) systems. The main reason for the statistical improvement with the optimal method over the fixed classification systems is the inaccurate positioning of the reference mid-drought threshold levels. For example, the three reference systems propose a fixed threshold for "severe" drought around the 10th precipitation percentile, while empirically it converges among all climate regions in South America and seasons to the 20th percentile-independent of the number of optimized drought categories. Indeed, this situation poses a problem for the early mitigation of meteorological drought impacts. The "severe" drought threshold level was found to be an effective starting point of a meteorological drought for the region in all optimized classification systems and the effective actions based on the reference classification systems may be delayed because of the underestimation of its onset. Nonetheless, at the higher intensity drought categories, namely at "extreme" and "exceptional" levels, the Agnew (2000) and Svoboda et al. (2002) reference systems, respectively, are able to approximately detect the empirical frequency of the respective events.

Considering the optimized classification of drought intensity threshold levels, some geographical variations in the monthly frequency of meteorological drought events are obtained throughout the study area in Latin America. Indeed, the optimized system not only classifies drought intensity threshold levels more accurately than the reference systems, but also has the unique ability 

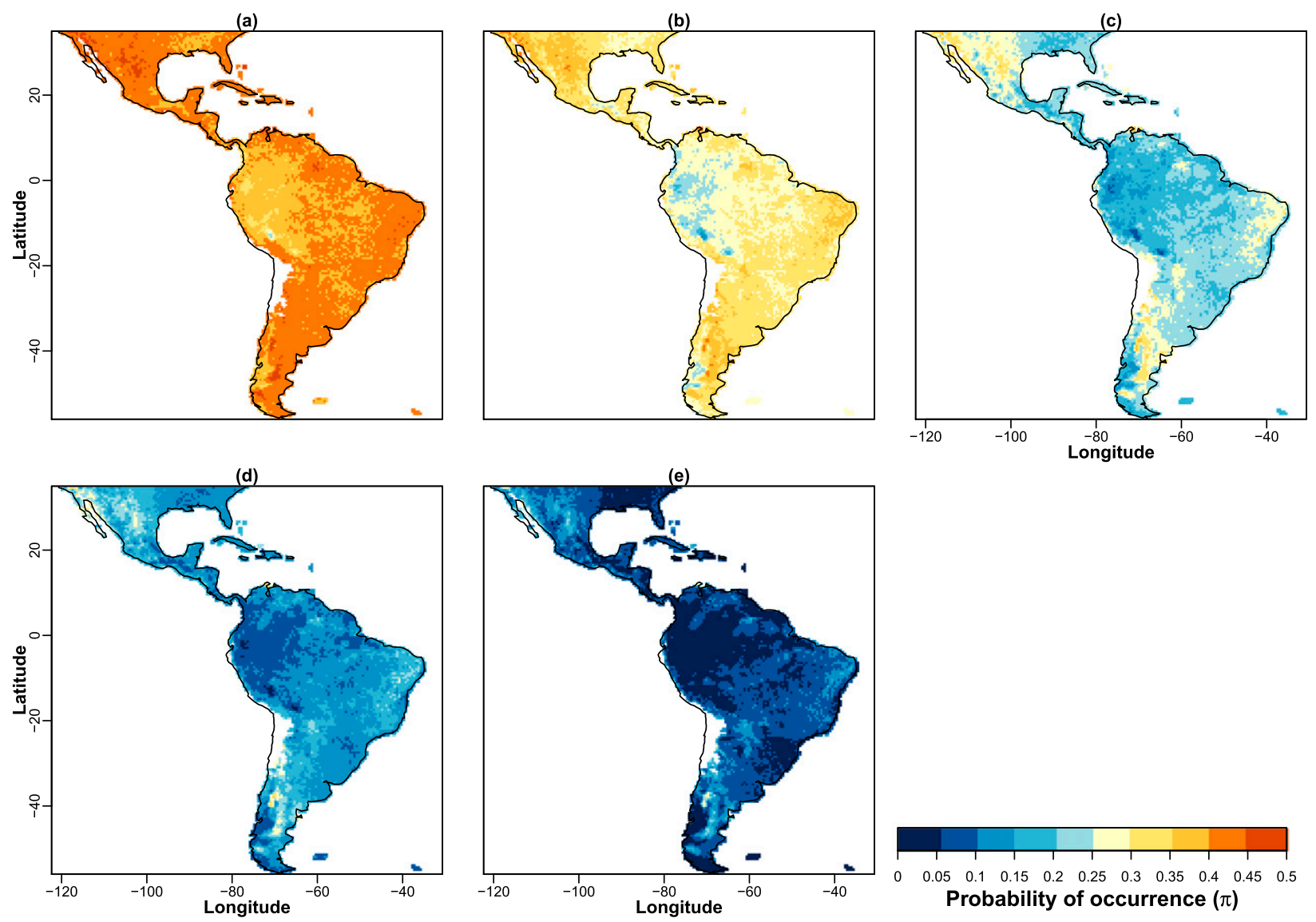

FIG. 9. Long-term probability of drought occurrence $(\pi)$ for different intensity categories: (a) "abnormally dry"; (b) "moderate”; (c) "severe"; (d) "extreme"; (e) "exceptional." The drought intensity classification system was defined with six categories. Grid cells with $<5$ nonzero historical precipitation records below the median are masked out in white.

to specifically measure the frequency of meteorological drought events in space and time. In opposition to the reference classification systems with fixed threshold levels, the frequency of "severe" meteorological drought events in the study area follows the distribution of climate conditions, as represented by the Köppen-Geiger classification. In particular, the arid regions are characterized by a higher meteorological drought frequency. Some research and policy implications are apparent from the conclusion that meteorological drought frequency can be accurately represented in space and time for different drought intensity categories. Drought mitigation plans can take advantage of this classification approach and reduction of impacts is possible if meteorological drought frequency and intensity are properly quantified, followed by specific investments in adapted measures aimed at local vulnerability reduction.

So far, experience shows that the position where the meteorological drought thresholds lie is fixed and/or entirely the analyst's decision. Our method guarantees an adapted threshold level classification that follows the natural breaks in the precipitation data distribution and avoids a bias in the estimation of meteorological drought onset. The proposed classification approach can then be used as a basis for the accurate estimation of the return period of meteorological droughts with different lengths, as well as of their expected interarrival time. Thus, future work will focus on the assessment of historic changes in meteorological drought over the last century, as well as on the study of its frequency and severity in the future as a result of climate change.

Acknowledgments. This research received support from the EUROCLIMA regional cooperation program between the European Union (European Commission; DG DEVCO) and Latin America.

\section{REFERENCES}

Agnew, C. T., 2000: Using the SPI to identify drought. Drought Network News, Vol. 12, National Drought Mitigation Center, 
Lincoln, NE, 6-12. [Available online at http://digitalcommons.unl. edu/cgi/viewcontent.cgi?article $=1000 \&$ context $=$ droughtnetnews. $]$

Allen, S. K., and Coauthors, 2012: Summary for policymakers. Managing the Risks of Extreme Events and Disasters to Advance Climate Change Adaptation, C. B. Field et al., Eds., Cambridge University Press, 1-19. [Available online at https:// www.ipcc.ch/pdf/special-reports/srex/SREX_Full_Report.pdf.]

Armstrong, M. P., N. Xiao, and D. A. Bennett, 2003: Using genetic algorithms to create multicriteria class intervals for choropleth maps. Ann. Assoc. Amer. Geogr., 93, 595-623, doi:10.1111/ 1467-8306.9303005.

Caccamo, G., L. Chisholm, R. Bradstock, and M. Puotinen, 2011: Assessing the sensitivity of MODIS to monitor drought in high biomass ecosystems. Remote Sens. Environ., 115, 2626-2639, doi:10.1016/j.rse.2011.05.018.

Carrão, H., G. Sepulcre, S. Horion, and P. Barbosa, 2013: A multitemporal and non-parametric approach for assessing the impacts of drought on vegetation greenness: A case study for Latin America. EARSeL eProc., 12, 8-24, doi:10.12760/ 01-2013-1-02.

Cormack, R. M., 1971: A review of classification. J. Roy. Stat. Soc., 134, 321-367, doi:10.2307/2344237.

Cromley, R., and R. Mrozinski, 1997: An evaluation of classification schemes based on the statistical versus the spatial structure properties of geographic distribution in choropleth mapping. Proc. 13th Annual Auto-Carto Symp. and Exposition, Seattle, WA, Cartography and Geopgraphic Information Society, 76-85.

Dracup, J. A., K. S. Lee, and E. G. Paulson Jr., 1980: On the definition of droughts. Water Resour. Res., 16, 297-302, doi:10.1029/ WR016i002p00297.

Fisher, W. D., 1958: On grouping for maximum homogeneity. J. Amer. Stat. Assoc., 53, 789-798, doi:10.1080/01621459.1958.10501479.

Gong, X., and M. B. Richman, 1995: On the application of cluster analysis to growing season precipitation data in North America east of the Rockies. J. Climate, 8, 897-931, doi:10.1175/ 1520-0442(1995)008<0897:OTAOCA $>2.0 . C O ; 2$.

Goodrich, G. B., and A. W. Ellis, 2006: Climatological drought in Arizona: An analysis of indicators for guiding the governor's drought task force. Prof. Geogr., 58, 460-469, doi:10.1111/ j.1467-9272.2006.00582.x.

Gouveia, C., R. M. Trigo, and C. C. DaCamara, 2009: Drought and vegetation stress monitoring in Portugal using satellite data. Nat. Hazards Earth Syst. Sci., 9, 185-195, doi:10.5194/ nhess-9-185-2009.

Guttman, N. B., 1993: The use of L-moments in the determination of regional precipitation climates. J. Climate, 6, 2309-2325, doi:10.1175/1520-0442(1993)006<2309:TUOLMI >2.0.CO;2.

_ 1999: Accepting the standardized precipitation index: A calculation algorithm. J. Amer. Water Resour. Assoc., 35, 311322, doi:10.1111/j.1752-1688.1999.tb03592.x.

Hayes, M. J., M. D. Svoboda, D. A. Wilhite, and O. V. Vanyarkho, 1999: Monitoring the 1996 drought using the standardized precipitation index. Bull. Amer. Meteor. Soc., 80, 429-438, doi:10.1175/1520-0477(1999)080<0429:MTDUTS > 2.0.CO;2.

Heim, R. R., 2002: A review of twentieth-century drought indices used in the United States. Bull. Amer. Meteor. Soc., 83, 11491165.

Hofer, B., H. Carrão, and D. McInerney, 2012: Multidisciplinary forest fire danger assessment in Europe: The potential to integrate long-term drought information. Int. J. Spat. Data Infrastruct. Res., 7, 300-322, doi:10.2902/ 1725-0463.2012.07.art15.
Jenks, G. F., and F. C. Caspall, 1971: Error on choroplethic maps: Definition, measurement, reduction. Ann. Assoc. Amer. Geogr., 61, 217-244, doi:10.1111/j.1467-8306.1971.tb00779.x.

Keyantash, J., and J. A. Dracup, 2002: The quantification of drought: An evaluation of drought indices. Bull. Amer. Meteor. Soc., 83, 1167-1180.

Kottek, M., J. Grieser, C. Beck, B. Rudolf, and F. Rubel, 2006: World map of the Köppen-Geiger climate classification updated. Meteor. Z., 15, 259-263, doi:10.1127/ 0941-2948/2006/0130.

Kumar, M. N., C. S. Murthy, M. V. R. S. Sai, and P. S. Roy, 2009: On the use of Standardized Precipitation Index (SPI) for drought intensity assessment. Meteor. Appl., 16, 381-389, doi:10.1002/met.136.

Llano, M. P., W. Vargas, and G. Naumann, 2012: Climate variability in areas of the world with high production of soya beans and corn: Its relationship to crop yields. Meteor. Appl., 19, 385-396, doi:10.1002/met.270.

Lloyd-Hughes, B., and M. A. Saunders, 2002: A drought climatology for Europe. Int. J. Climatol., 22, 1571-1592, doi:10.1002/ joc. 846 .

Logar, I., and J. C. J. M. van den Bergh, 2011: Methods for assessment of the costs of droughts. CONHAZ Rep. WP05, $58 \mathrm{pp}$. [Available online at http://conhaz.org/ CONHAZ\%20REPORT\%20WP05_1_FINAL.pdf.]

Magrin, G., C. G. Garca, D. C. Choque, J. C. Gimnez, A. R. Moreno, G. J. Nagy, C. Nobre, and A. Villamizar, 2007: Latin America. Climate Change 2007: Impacts, Adaptation and Vulnerability, M. L. Parry et al., Eds., Cambridge University Press, 581-615. [Available online at http://www.ipcc.ch/pdf/ assessment-report/ar4/wg2/ar4-wg2-chapter13.pdf.]

Maidment, D. R., 1993: Handbook of Hydrology. McGraw-Hill, $1424 \mathrm{pp}$

Makkonen, L., 2006: Plotting positions in extreme value analysis. J. Appl. Meteor. Climatol., 45, 334-340, doi:10.1175/ JAM2349.1.

McKee, T. B., N. J. Doeskin, and J. Kleist, 1993: The relationship of drought frequency and duration to time scales. Proc. Eighth Conf. on Applied Climatology, Anaheim, CA, Amer. Meteor. Soc., 179-184.

Meyer, V., and Coauthors, 2013: Review article: Assessing the costs of natural hazards-State of the art and knowledge gaps. Nat. Hazards Earth Syst. Sci., 13, 1351-1373, doi:10.5194/ nhess-13-1351-2013.

Mishra, A. K., and V. P. Singh, 2011: Drought modeling-A review. J. Hydrol., 403, 157-175, doi:10.1016/j.jhydrol.2011.03.049.

- — - and V. R. Desai, 2009: Drought characterization: A probabilistic approach. Stochastic Environ. Res. Risk Assess., 23, 41-55, doi:10.1007/s00477-007-0194-2.

Morid, S., V. Smakhtin, and M. Moghaddasi, 2006: Comparison of seven meteorological indices for drought monitoring in Iran. Int. J. Climatol., 26, 971-985, doi:10.1002/ joc.1264.

Naumann, G., P. Barbosa, H. Carrão, A. Singleton, and J. Vogt, 2012: Monitoring drought conditions and their uncertainties in Africa using TRMM data. J. Appl. Meteor. Climatol., 51, 18671874, doi:10.1175/JAMC-D-12-0113.1.

Ntale, H. K., and T. Y. Gan, 2003: Drought indices and their application to East Africa. Int. J. Climatol., 23, 1335-1357, doi:10.1002/joc. 931 .

Panu, U., and T. Sharma, 2002: Challenges in drought research: Some perspectives and future directions. Hydrol. Sci. J., 47, 19-30, doi:10.1080/02626660209493019. 
Paulo, A. A., E. Ferreira, C. Coelho, and L. S. Pereira, 2005: Drought class transition analysis through Markov and loglinear models, an approach to early warning. Agric. Water Manage., 77, 59-81, doi:10.1016/j.agwat.2004.09.039.

Phillips, O. L., and Coauthors, 2009: Drought sensitivity of the Amazon rainforest. Science, 323, 1344-1347, doi:10.1126/ science. 1164033.

Quiring, S. M., 2009: Developing objective operational definitions for monitoring drought. J. Appl. Meteor. Climatol., 48, 12171229, doi:10.1175/2009JAMC2088.1.

Rudolf, B., A. Becker, U. Schneider, A. Meyer-Christoffer, and M. Ziese, 2011: New GPCC Full Data Reanalysis Version 5 provides high-quality gridded monthly precipitation data. GEWEX News, Vol. 21, International GEWEX Project Office, Silver Spring, MD, 4-5.

Santos, J. F., I. Pulido-Calvo, and M. M. Portela, 2010: Spatial and temporal variability of droughts in Portugal. Water Resour. Res., 46, W03503, doi:10.1029/2009WR008071.

Sepulcre-Canto, G., S. Horion, A. Singleton, H. Carrão, and J. Vogt, 2012: Development of a Combined Drought Indicator to detect agricultural drought in Europe. Nat. Hazards Earth Syst. Sci., 12, 3519-3531, doi:10.5194/nhess-12-3519-2012.

Sheffield, J., K. M. Andreadis, E. F. Wood, and D. P. Lettenmaier, 2009: Global and continental drought in the second half of the twentieth century: Severity-area-duration analysis and temporal variability of large-scale events. J. Climate, 22, 19621981, doi:10.1175/2008JCLI2722.1.

Slocum, T. A., R. B. McMaster, F. C. Kessler, and H. H. Howard, 2008: Thematic Cartography and Geovisualization. 3rd ed. Prentice Hall, 576 pp.

Smakhtin, V. U., and E. L. F. Schipper, 2008: Droughts: The impact of semantics and perceptions. Water Policy, 10, 131-143, doi:10.2166/wp.2008.036.

Steinemann, A., 2003: Drought indicators and triggers: A stochastic approach to evaluation. J. Amer. Water Resour. Assoc., 39, 1217-1233.

_- , and L. Cavalcanti, 2006: Developing multiple indicators and triggers for drought plans. J. Water Resour. Plann. Manage., 132, 164-174, doi:10.1061/(ASCE)0733-9496(2006)132: 3(164).

Svoboda, M., and Coauthors, 2002: The Drought Monitor. Bull. Amer. Meteor. Soc., 83, 1181-1190.
—, M. Hayes, and D. Wood, 2012: Standardized precipitation index user guide. World Meteorological Organization Tech. Rep. WMO-1090, 24 pp. [Available online at http://library.wmo.int/ opac/index.php?lvl=notice_display\&id=13682\#.U6nTbvldVik.]

Traun, C., and M. Loidl, 2012: Autocorrelation-based regioclassification-A self-calibrating classification approach for choropleth maps explicitly considering spatial autocorrelation. Int. J. Geogr. Inf. Sci., 26, 923-939, doi:10.1080/ 13658816.2011.614246.

Trenberth, K., and D. Stepaniak, 2001: Indices of El Niño evolution. J. Climate, 14, 1697-1701, doi:10.1175/1520-0442(2001)014<1697: LIOENO $>2.0 . \mathrm{CO} ; 2$.

Vargas, W. M., G. Naumann, and J. L. Minetti, 2011: Dry spells in the River Plata Basin: An approximation of the diagnosis of droughts using daily data. Theor. Appl. Climatol., 104, 159173, doi:10.1007/s00704-010-0335-2.

Vicente-Serrano, S. M., 2006: Spatial and temporal analysis of droughts in the Iberian Peninsula (1910-2000). Hydrol. Sci. J., 51, 83-97, doi:10.1623/hysj.51.1.83.

_ - J. C. González-Hidalgo, M. de Luis, and J. Raventós, 2004: Drought patterns in the Mediterranean area: The Valencia region (eastern Spain). Climate Res., 26, 5-15, doi:10.3354/cr026005.

_ _ S. Beguería, and J. I. López-Moreno, 2010: A multiscalar drought index sensitive to global warming: The standardized precipitation evapotranspiration index. J. Climate, 23, 16961718, doi:10.1175/2009JCLI2909.1.

Weibull, W., 1939: The Phenomenon of Rupture in Solids. Handlingar, Vol. 153, Ingeniörs Vetenskaps Akademien, 45 pp.

Wilhite, D. A., and M. H. Glantz, 1985: Understanding the drought phenomenon: The role of definitions. Water Int., 10, 111-120, doi:10.1080/02508068508686328.

Wilks, D. S., 2005: Statistical Methods in the Atmospheric Sciences: An Introduction. 2nd ed. Academic Press, 648 pp.

Wu, H., M. J. Hayes, D. A. Wilhite, and M. D. Svoboda, 2005: The effect of the length of record on the standardized precipitation index calculation. Int. J. Climatol., 25, 505-520, doi:10.1002/ joc.1142.

Yadav, S., R. Redden, J. Hatfield, H. Lotze-Campen, and A. Hall, 2011: Crop Adaptation to Climate Change. Wiley, 624 pp.

Zhao, M., and S. W. Running, 2010: Drought-induced reduction in global terrestrial net primary production from 2000 through 2009. Science, 329, 940-943, doi:10.1126/science.1192666. 